\title{
The Optimisation of Surface Roughness using Extreme Learning Machine and Particle Swarm Optimization
}

\author{
Tiagrajah V. Janahiraman*, Nooraziah Ahmad \\ Centre for Signal Processing and Control Systems, Dept. of Electronics and Communication Engineering, College of \\ Engineering, Universiti Tenaga Nasional, Jalan IKRAM-UNITEN, 43000 Kajang, Selangor, Malaysia. \\ Email: tiagrajah@uniten.edu.my \\ Tuan Ab Rashid bin Tuan Abdullah \\ Institute of Energy Policy and Research (IEPRe), Universiti Tenaga Nasional, Jalan IKRAM-UNITEN, 43000 Kajang, \\ Selangor, Malaysia.
}

\begin{abstract}
In recent days, metal cutting has become a highly demanding sector due to growing applications. The turning process is one of the metal cutting processes which produces circular shapes from a cylindrical bar. Currently, turning operation is conducted using computer numerical control machine (CNC). The machinist is required to assign the optimal cutting parameters in CNC turning which have direct influence on the performance of each cutting process. Therefore, it is crucial to achieve the optimal parameters before the process is started. In usual cases, these parameters will be assigned according to machinist's past experience or with reference to the manual handbook provided by the tool supplier. However, this approach can be considered time consuming and do not guarantee that it can produce the desired cutting performance. In light of this issue, a new optimisation technique has been proposed to figure out the optimal cutting parameters. Box Behnken's design is used as the experimental design, while the improved Extreme Learning Machine which is based on Particle Swarm Optimisation is proposed as the prediction model. A powerful and effective, Particle Swarm Optimisation will act as the optimiser of the prediction model. The turning parameters: cutting speed, feed rate and depth of cut, are considered as the input variables to the model. The optimisation results prove that the system is able to predict well and generate optimal cutting parameters to minimize the surface roughness of the machined workpiece.
\end{abstract}

Index Terms - optimization, surface roughness, particle swarm, extreme learning machine

\section{INTRODUCTION}

Turning can be described as a machining process which is involved in the production of circular shapes from a cylindrical bar. The most common process parameters that are used in the turning operation include feed rate, cutting speed and depth of cut which are considered as the variables that could control the process and affect the machining performance. These three

Manuscript received April 7, 2018; revised December 7, 2018. parameters are easy to be manipulated by the technician which directly influences the cutting performance. Furthermore, Park et al and Mukherjee et al analysed and concluded that it can accommodate the machinist to increase both the profit and productivity as well as to produce better quality $[1,2]$.

In the real industrial environment, the machinist will use their experience or manual handbook to get the optimal parameters to conduct the turning operation. However, these parameters are not guaranteed to be optimal. Hence, a trial and error experiment must be carried out for a few times before achieving the optimal value. Therefore, an optimisation technique is needed to obtain the optimal value as well as to produce high quality product within a short period of time without increasing the production cost.

The quality of a product often refers to the surface roughness of the machined product $[3,4]$. There are quite a number of researches that have been conducted to optimise the surface roughness regardless of the machining processes [5-7]. Dayanand and Nalbant have used the Taguchi method to obtain the optimal value for the minimum surface roughness [5, 8]. However, this method has its drawbacks despite the fact that it is often preferred by most researchers because of its simplicity. The solution provided by Taguchi method often falls into local optima [9-11]. Therefore, Artificial Intelligent (AI) based system is used to achieve a particular goal especially when dealing with high dimensional search space with many local optima [11]. The AI is capable of handling non-linear response function and constraint problem. Routara et al. and Subramaniam et al. have used an artificial intelligent system which is known as the genetic algorithm (GA) to optimise the cutting parameters in their researches [12, 13]. Raja found that the parameters obtained using the Particle Swarm Optimization (PSO) are able to produce better surface roughness in a minimum possible machining time [14]. 
Apart from that, Huang et al. proposed an algorithm for hidden nodes determination and weight selection which is called Extreme Learning Machine (ELM) [16]. The main advantages of this modelling approach include the role of ELM which simplifies the neural network methods as well as the modelling of the process performance that occurs in an extraordinarily short time [17]. ELM also requires less user-defined parameters and possesses similar structure as single layer feedforward neural network (SLFN) with an analytically determined output weight. In 2015, Ahmad et al conducted a research on modelling techniques using ELM, Neural Network (ANN), Support Vector Machine (SVM) and Response Surface Methodology (RSM) [18]. The results reveal that ELM performs better when compared to other techniques in terms of the prediction accuracy and the training speed.

In 2006, Xu and Shu introduced a hybrid approach which combine ELM with Particle Swarm Optimization (PSO) [24]. This idea can achieve good generalization performance when compared to ELM alone.

In this study, a combination of the Box-Behnken design-Extreme Learning Machine based Particle Swarm Optimization (BBD-ELMPSO) for modelling and PSO as the optimization technique is proposed to determine the optimal cutting parameters in turning operation. This method aims to determine the optimal cutting parameters in the proper and fastest method. The rest of the paper is organised as follows: the proposed method will be explained in Section 2 while the experimental setup and cutting conditions are defined in Section 3. Section 4 validates the results and finally, this study is concluded in Section 5.

\section{PROPOSED METHOD}

The proposed optimisation method is a combination of statistical and artificial intelligent techniques. It contains three stages, which are experimental data collection, modelling and optimisation.

For the first stage, the statistical technique is selected to generate the data set for the modelling technique. In this stage, the lowest number of data set will be identified as well as the best prediction accuracy need to be achieved for the cutting performance.

According to Ahmad et al, Box-Benhken Design (BBD) with Response Surface Methodology (RSM) is the most reliable experimental design that could be used in predicting the performance function of machining [15]. The case study conducted by the author shows that for three levels and three factors experiments, the BBD provided the smallest number of experiments, which is fifteen, and produced smaller average variance compared to others experimental designs. For this reason, BBD has been chosen as the experimental design in the modelling technique, which uses three level-factors.

The combination of ELM and PSO is used as the modelling technique. This approach has been approved by $\mathrm{Xu}$ and $\mathrm{Shu}$ as the fastest and has good generalization achievement when compared to conventional ELM [24].

The ELM contains an input layer, a hidden layer and an output layer. The connection between the layers is represented by the weight $(w)$. The input weight and bias for ELM are randomly assigned during the modelling process. Unlike the traditional SLFN, the weight present in ELM does not need to be tuned and able to perform well even with limited data [19]. The ELM can work by finding the output weight $(\hat{\beta})$ using Moore-Penrose generalised inverse matrix provided by Equation 1 [20].

$$
\widehat{\beta}=H^{\dagger} T
$$

where $H$ is the hidden output.

$$
H=\left(\begin{array}{ccc}
f\left(w_{1} x_{1}+b_{1}\right) & \ldots & f\left(w_{N} x_{1}+b_{N}\right) \\
\vdots & \ddots & \vdots \\
f\left(w_{1} x_{M}+b_{1}\right) & \ldots & f\left(w_{N} x_{M}+b_{N}\right)
\end{array}\right)
$$

and $T$ is the target, $T=\left(T_{1}, \ldots, T_{N}\right)^{T}$. The ELM is considered to reach the solution when it has achieved the following properties.

\section{A. Minimum training error

$$
\min \|H \hat{\beta}-T\|
$$

\section{B. Smallest norm of weight}

$$
\min \|\hat{\beta}\|
$$

The prediction result often ends up being unsatisfactory because the ELM input weight and hidden bias are always chosen randomly. Hence, the PSO technique is utilised as the solution for this problem. The details of the modelling method has been explained in the authors' research paper [21]. The advantage of combining ELM with PSO includes the fact that only minimum number of parameters are needed to be adjusted. It takes real number as particles while the norm of output weights is decreased during training process. Other than that, the input weight and hidden biases are constrained within a reasonable range in order to improve the ELM performance.

The PSO, which is introduced by Kennedy and Eberhart [22], is applied to find the input weight and bias that could fit the prediction model. The swarm refers to the population while the potential solution refers to the particle inside PSO. The velocity of each particle is determined and modified according to the local best position and the global best position. The local best position is the particle at its best from within the restricted local neighbourhood while the global best position is the best particle that comes from the entire swarm.

The velocity calculation is shown in the equation below.

$$
\begin{gathered}
v_{i}^{k+1}=w v_{i}^{k}+c_{1} R_{1}\left(p_{i}-x_{i}^{k}\right)+c_{2} R_{2}\left(p_{g}-x_{i}^{k}\right) \\
x_{i}^{k+1}=x_{i}^{k}+v_{i}^{k+1}
\end{gathered}
$$


where $w$ is the inertia weight, while $c_{1}$ and $c_{2}$ refers to the local and global acceleration coefficients, respectively with the interval of $0<c_{1}, c_{2} \leq 2$.

In this study, the particles act as the input weights and biases, which are randomly initialised. The fitness value refers to the error on the validation set of data, which is calculated based on Box Behnken Design - Extreme Learning Machine - Particle Swarm Optimisation (BBDELMPSO). The velocity of each particle is iteratively modified by its personal best position $p_{1}$ and the global best position $p_{g}$. The $c_{1}$ and $c_{2}$ are set to be 2 while $w$ is equal to 1 . The process is repeated until the stop criterion is met, which is the minimum prediction error of the test data set and the smallest norm of output weight. The result achieved after the computation of this algorithm, will be the input weight and bias which has the lowest validation error among its population.

In final stage, the PSO, is again used as the optimisation method for the predicted model. Therefore, the overall optimisation method proposed by the author is BBD-ELMPSO-PSO. The PSO, which has been successfully applied in the modelling stage, will be implemented to determine the optimal cutting parameters for the turning operation. In contrast to the modelling technique, the particle in the optimisation will be represented by cutting parameters such as cutting speed, feed rate and depth of cut. The ELMPSO model will be the fitness function, in which the fitness value refers to the minimum surface roughness while other constants in the algorithm will remain the same for the optimisation technique. Fig. 1 shows the diagram of overall system which summarizes the whole process.

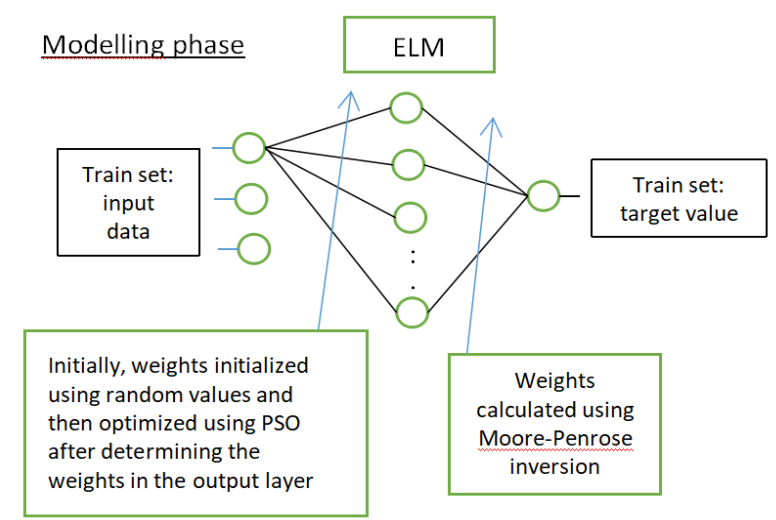

\section{Optimal parameter calculation phase}

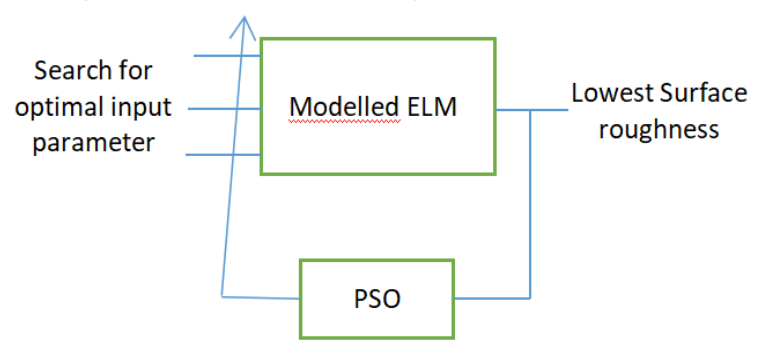

Figure 1. Diagram describing the overall system

\section{EXPERIMENTAL SETUP AND CUTTING CONDITIONS}

In this study, the experiment was conducted on CNC lathe machine using CNMG 120404NGU AC603. The workpiece used in this experiment is a medium carbon steel grade AISI 1045 with the length of $100 \mathrm{~mm}$ and a diameter of $20 \mathrm{~mm}$.

The chemical and physical properties of the workpiece material are shown in Table I. Table II presents the parameters for the experimental design.

The experimental data consists of 15 experiments in which each experiment was stopped after $40 \mathrm{~mm}$ cutting length is reached. The new cutting edge was used in each experiment to ensure the accuracy of the reading. The measurement of the surface roughness was recorded using the surface roughness tester, Rugosurf 100. The samples were measured three times at different locations and the average surface roughness for each samples is recorded.

TABLE I. MATERIAL PROPERTIES OF AISI 1045.

\begin{tabular}{|c|c|c|c|}
\hline $\begin{array}{c}\text { Chemical } \\
\text { properties }\end{array}$ & $\begin{array}{c}\text { Physical } \\
\text { properties }\end{array}$ & \\
\hline $\mathrm{C}(\%)$ & $0.42-0.50$ & $\begin{array}{c}\text { Tensile } \\
\text { strength (MPa) }\end{array}$ & 595 \\
\hline $\mathrm{Mn}(\%)$ & $0.60-0.90$ & $\begin{array}{c}\text { Yield strength } \\
\text { (MPa) }\end{array}$ & 310 \\
\hline $\mathrm{P}(\%)$ & $0.04(\max )$ & $\begin{array}{c}\text { Reduction of } \\
\text { area (\%) }\end{array}$ & 40 \\
\hline $\mathrm{S}(\%)$ & $0.05(\max )$ & Elongation (\%) & 16 \\
\hline
\end{tabular}

TABLE II. THE INPUT VARIABLES.

\begin{tabular}{|c|c|c|c|}
\hline Levels & Low & Medium & High \\
\hline $\begin{array}{c}\text { Cutting speed } \\
(\mathrm{m} / \mathrm{s})\end{array}$ & 80 & 90 & 100 \\
\hline $\begin{array}{c}\text { Feed rate } \\
\text { (mm/rev) }\end{array}$ & 0.1 & 0.15 & 0.2 \\
\hline $\begin{array}{c}\text { Depth of cut } \\
(\mathrm{mm})\end{array}$ & 0.8 & 0.9 & 1 \\
\hline
\end{tabular}

The 15 experimental data are used as the training data set and the three data in the training were applied as the test data set.

For the optimisation process, some technological constraints need to be fulfil [23], which depend on the manual handbook or experimental work conducted on selected machine tool, cutting tool and workpiece. The constraints in this study involves cutting parameters which are defined within an upper and lower permissible limit, given in Equations 7, 8 and 9.

$$
\begin{gathered}
\text { Cutting speed: } 80 \leq v \leq 100 \\
\text { Feed rate: } 0.1 \leq f \leq 0.2 \\
\text { Depth of cut: } 0.8 \leq d \leq 1
\end{gathered}
$$

In order to validate the result, the mean absolute error (MAE) is computed, which is given in Equation 10.






\section{COMPutational RESUlts}

For the first stage, BBD with 15 number of experiments is carried out on CNC machine to obtain the surface roughness. The results are tabulated in Table III.

TABLE III. EXPERIMENTAL RESULTS.

\begin{tabular}{|c|c|}
\hline Experiment No. & Surface roughness $(\mu \mathrm{m})$ \\
\hline 1 & 7.29 \\
\hline 2 & 3.93 \\
\hline 3 & 6.87 \\
\hline 4 & 4.48 \\
\hline 5 & 3.93 \\
\hline 6 & 6.18 \\
\hline 7 & 6.59 \\
\hline 8 & 4.91 \\
\hline 9 & 2.8 \\
\hline 10 & 2.52 \\
\hline 11 & 2.72 \\
\hline 12 & 2.94 \\
\hline 13 & 4.11 \\
\hline 14 & 4.31 \\
\hline 15 & 3.93 \\
\hline
\end{tabular}

Then, the BBD data is fed into ELMPSO to model the cutting performance. The prediction accuracy for BBDELMPSO model is shown in Table IV. It managed to perform well compared to the conventional ELM in predicting the cutting performance. The prediction error calculation is based on the mean absolute error (MAE) presented in Equation 10.

The BBD-ELMPSO was able to predict the test data set with the lowest accuracy of 0.0162 and the norm of output weight of 6.4594. Meanwhile, the MAE for ELM is recorded to be 0.1438 , which is more than the BBDELMPSO with the norm of output weight of 8.8284 .

TABLE IV. The AcCuracy For the EXPERIMENTAL Test DATA Set.

\begin{tabular}{|c|c|c|c|}
\hline Exp. No. & $\begin{array}{c}\text { Measured } \\
\text { surface } \\
\text { roughness } \\
(\mu \mathrm{m})\end{array}$ & $\begin{array}{c}\text { Predicted by } \\
\text { conventional } \\
\text { ELM }(\mu \mathrm{m})\end{array}$ & $\begin{array}{c}\text { Predicted by } \\
\text { BBD- } \\
\text { ELMPSO } \\
(\mu \mathrm{m})\end{array}$ \\
\hline 1 & 3.01 & 2.8843 & 3.0188 \\
\hline 2 & 4.94 & 4.6340 & 4.9014 \\
\hline 3 & 2.98 & 2.9317 & 2.9788 \\
\hline
\end{tabular}

In terms of computational time, conventional ELM takes 0.2 seconds to accomplish the task while BBDELMPSO needs 0.7 seconds to complete the same task. It is consider fast as it only takes less than 1 second to complete the prediction model yet gives very accurate prediction.

For final stage, the results of optimal cutting parameters obtained after PSO being applied on BBDELMPSO model are shown in Table V. These optimal values, according to our simulation will produce a surface roughness of $1.1919 \mu \mathrm{m}$.

Next, a confirmation experiment was conducted to validate the effectiveness of the suggested optimal parameters. The measured surface roughness is $2.28 \mu \mathrm{m}$, as shown in Table $\mathrm{V}$, which provide an acceptable MAE recorded at 1.01 .

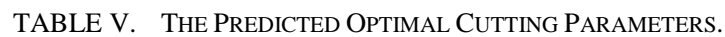

\begin{tabular}{|c|c|c|c|c|c|}
\hline & $v$ & $f$ & $d$ & $\begin{array}{c}\text { Predicted } \\
\text { value }(\mu \mathrm{m})\end{array}$ & $\begin{array}{c}\text { Measured } \\
\text { value }(\mu \mathrm{m})\end{array}$ \\
\hline $\begin{array}{c}\text { Proposed } \\
\text { method }\end{array}$ & 100 & 0.1 & 0.8 & 1.1919 & 2.28 \\
\hline
\end{tabular}

The developed algorithm possesses the following advantages:

1. Extraordinarily fast modelling and optimisation technique.

2. Less time consuming in the determination of the training parameters.

3. Simple and easy implementation in using users' experimental data.

\section{CONCLUSION}

In this study, BBD-ELMPSO and PSO approach are proposed to optimise the cutting parameters for surface roughness in the turning operation. The machinist will never need to assume the cutting parameters or run trial and error experiments as the proposed method elaborates proper steps in attaining the optimal value. The proposed modelling method is fast in training the parameters. The method is also proved to be accurate and requires less adjustable parameters. The Particle Swarm Optimisation provides a sufficient approximation to the true optimal solution. This global approach is fast, less time consuming and easy to implement due to the less parameter required. The optimal values of feed rate, cutting speed and depth of cut calculated using our proposed method, were used as input parameters for the CNC machine. The surface roughness obtained from the cutting was very close to our simulated result. As a part of future work, this approach can be applied to optimise other types of machining process, extend the work to multi objective optimisation problem and design an interface for easy user interaction.

\section{ACKNOWLEDGMENT}

The authors wish to thank Techno Centre Kulim HiTech for allowing us to use their equipment and machinery.

\section{REFERENCES}

[1] K. S. Park and S. H. Kim, "Artificial intelligent approaches to determination of CNC machining parameters in manufacturing: A review," Artificial Intelligence in Engineering, vol. 12, pp. 127134, 1997.

[2] I. Mukherjee and P. K. Ray, "A review of optimisation techniques in metal cutting processes," Computers and Industrial Engineering, vol. 50, pp. 15-34, 2006.

[3] R. Vinayagamoorthy and M. A. Xavior, "Investigations on the machinability of titanium alloy during precision turning," Middle- 
East Journal of Scientific Research, vol. 22, no. 12, pp. 1782-1787, 2014.

[4] A. M. Zain, H. Haron, S. Sharif, "Prediction of surface roughness in the end milling machining using artificial neural network," Expert Systems with Applications, vol. 37, no. 2, pp. 1755-1768, 2010.

[5] M. Nalbant, H. Gkkaya, and G. Sur, "Application of Taguchi method in the optimisation of cutting parameters for surface roughness in turning," Materials amp; Design, vol. 28, no. 4, 2007

[6] A. Aggarwal, H. Singh, P. Kumar, and M. Singh, "Optimization of multiple quality characteristics for CNC turning under cryogenic cutting environment using desirability function," Journal of Materials Processing Technology,vol. 205, no. 1, pp. 42-50, 2008.

[7] K. Kadirgama, M. M. Noor, and A. N. A. Alla, "Response ant colony optimization of end milling surface roughness," Sensors, vol. 10, no. 3, pp. 2054-2063, 2010.

[8] P. Dayanand, R. Shrikantha, and S. Raviraj, "Application of Taguchi and response surface methodologies for metal removal rate and surface roughness in grinding of Dracs," International Journal of Engineering and Management sciences, vol. 3, no. 1, 2012.

[9] A. Aggarwal, H. Singh, P. Kumar, M. Singh, "Optimizing power consumption for $\mathrm{CNC}$ turned parts using response surface methodology and Taguchi's techniquea comparative analysis," Journal of Materials Processing Technology, vol. 200, no. 1, pp. 373-384, 2008.

[10] S. Subramonian, S. A. Rahim, "Comparison between Taguchi Method and Response Surface Methodology (RSM) in modelling $\mathrm{CO} 2$ laser machining," Jordan Journal of Mechanical and Industrial Engineering, vol. 8, no. 1, pp. 35-42, 2014.

[11] I. Mukherjee, P. K. Ray, "A review of optimization techniques in metal cutting processes," Computers and Industrial Engineering, vol. 50, pp. 15-34, 2006.

[12] B. C. Routara, A. K. Sahoo, A. K. Parida, and P. C. Padhi, "Response surface methodology and genetic algorithm used to optimize the cutting condition for surface roughness parameters in CNC turning," Procedia Engineering, vol. 38, pp. 1893-1904, 2012.

[13] M. Subramanian, M. Sakthivel, K. Sooryaprakash, R. Sudhakaran, "Optimization of end mill tool geometry parameters for A17075T6 machining operations based on vibration amplitude by response surface methodology," Measurement, vol. 46, no. 10, pp. 4005-4022, 2013.

[14] S. B. Raja and N. Baskar, "Application of particle swarm optimization technique for achieving desired milled surface roughness in minimum machining time," Expert Systems with Applications, vol. 39, no. 5, pp. 5982-5989, 2012.

[15] N. Ahmad, T. V. Janahiraman, "A study on regression model using response surface methodology," Applied Mechanics and Materials, vol. 666, pp. 235-239, 2014.

[16] G. B. Huang, Q. Y. Zhu, C. K. Siew, "Extreme learning machine: a new learning scheme of feedforward neural networks.," in Proc. 2004 IEEE International Joint Conference on Neural Networks, vol. 2, pp. 985-990, 2004, July.

[17] Y. Miche, P. Bas, C. Jutten, O. Simula, and A. Lendasse, A Methodology for Building Regression Models using Extreme Learning Machine: OP-ELM. In ESANN, pp. 247-252, 2008, April.

[18] N. Ahmad, T. V. Janahiraman, and F. Tarlochan, "Modeling of surface roughness in turning operation using extreme learning machine," Arabian Journal for Science and Engineering, vol. 40, no. 2, pp. 595-602, 2015.

[19] C. Natarajan, S. Muthu, and P. Karuppuswamy, "Prediction and analysis of surface roughness characteristics of a non-ferrous material using ANN in CNC turning," The International Journal of Advanced Manufacturing Technology, vol. 57, no. 9-12, pp. 1043-1051, 2011.

[20] G. B. Huang, Q. Y. Zhu, and C. K. Siew, "Extreme learning machine: theory and applications," Neurocomputing, vol. 70, no. 1, pp. 489-501, 2006.
[21] N. Ahmad and T. V. Janahiraman, "Modelling and prediction of surface roughness and power consumption using parallel extreme learning machine based particle swarm optimization," Springer International Publishing, in Proc. ELM-2014, vol. 2, pp. 321-329, 2015.

[22] J. Kennedy and R. Eberhart, "Particle swarm optimization," in Proc. IEEE International Conf. on Neural Networks (Perth, Australia), IEEE Service Center, Piscataway, NJ, 1995.

[23] U. Zuperl, F. Cus, B. Mursec, and T. Ploj, "A hybrid analyticalneural network approach to the determination of optimal cutting conditions," Journal of Materials Processing Technology, vol. 157, pp. 82-90, 2004

[24] Y. Xu and Y. Shu, "Evolutionary extreme learning machine-based on particle swarm optimization," Advances in Neural Networks, pp. 644-652, 2006.



Tiagrajah V. Janahiraman received the $\mathrm{B}$ Electrical Engineering (Electronic) and $\mathrm{M}$. Engineering (Electrical) from Faculty of Electrical Engineering, Universiti Teknologi Malaysia in 2000 and 2002, respectively. In 2012, he completed his Phd in Electrical Engineering from the College of Engineering, Universiti Tenaga Nasional. He is currently a Senior Lecturer at the College of Engineering, Universiti Tenaga Nasional. His major research areas are image processing, intelligent systems and computer vision.



Nooraziah Ahmad received her Ph.D. degree in Industrial Science from Universiti Tenaga Nasional, Malaysia in 2017. Her Master degree is in Plastics product design from London Metropolitan University, United Kingdom and B.Eng. in CAD/CAM Engineering from Malaya University, Malaysia. She is currently an Assistant Professor with the Faculty of Creative Technology and Heritage, Universiti Malaysia Kelantan, Malaysia. Her research interest include computational intelligence, CAD/CAM and manufacturing.

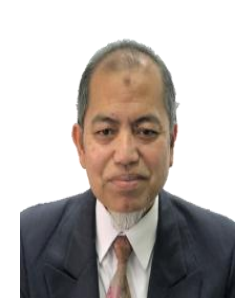

Prof Ir Dr Tuan Ab Rashid bin Tuan Abdullah has served Universiti Tenaga Nasional and Tenaga Nasional Berhad (TNB) for 12 years and 20 years respectively. His experience in electrical engineering and business management include network expansion, operation, maintenance, automation, communication, control, technical examiner, system design and electricity supply performance management, development of electricity billing system, electricity tariff formulation and field trial of two-way smart meter in TNB, He has hold various positions in UNITEN and TNB including Deputy Dean, Laboratory Manager, Head of Smart Grid Center, Representative for IP Protection at MyIPO, Director of Consulting Unit and Director of the Institute of Energy Policy \& Research. His consulting works includes the development of electricity blueprint infrastructure for Iskandar Malaysia the harmonic study on KTMB double tracking, digital model of $33 \mathrm{kV}$ overhead system for transient analysis, warehousing management in integrated supply chain, and greenhouse gas inventory on energy and industrial process \& product use in Malaysia. His current research include magnetic field generator design, application of satellite stereo imagery for vegetation management near transmission line, life-cycle cost-analysis of major components in power system, economic efficiency of alternative energy mix. 